\title{
Food Webs
}

December 2017, Volume 13, Pages 33-37

http://dx.doi.org/10.1016/i.fooweb.2017.08.001

http://archimer.ifremer.fr/doc/00395/50614/

(c) 2017 Published by Elsevier Inc.

\section{Investigating feeding ecology of two anglerfish species, Lophius piscatorius and Lophius budegassa in the Celtic Sea using gut content and isotopic analyses}

\author{
Issac Pierre ${ }^{1,2}$, Robert Marianne ${ }^{2}$, Le Bris Hervé ${ }^{1}$, Rault Jonathan ${ }^{2}$, Pawlowski Lionel ${ }^{2}$, Kopp \\ Dorothee $^{2}$
}

${ }^{1}$ ESE, Ecology and Ecosystem Health, Agrocampus Ouest, INRA, 35042, Rennes, France

${ }^{2}$ Ifremer, Unité de Sciences et Technologies Halieutiques, Laboratoire de Technologie et Biologie Halieutique, 8 rue François Toullec, F-56100, Lorient, France

\begin{abstract}
:
We used stable isotope ratio and gut content analyses to determine and compare the feeding ecology of two commercially important predator species, Lophius piscatorius and Lophius budegassa in the Celtic sea, where data concerning their trophic ecology remain sparse. This study included two areas and two size-classes, showing that anglerfish in the Celtic sea are mainly piscivorous top predators as observed in other marine waters. However, a substantial part of the diet of the fish in the small size classes consists of benthic macro-invertebrates, mainly Crustaceans. Despite the common knowledge that they are opportunistic predators that display a low degree of prey selectivity, our results suggest that the two species have different trophic niches when they occur in the same area. In the shallow area, both small and large individuals of $L$. budegassa seemed to prefer Crustacean prey, whereas L. piscatorius showed a clear shift from Crustaceans to fish prey with increasing size-class in the two areas. Stable isotope data analysis support the common finding that trophic level increases with body size for $L$. piscatorius and that overlaps between the isotopic niche spaces are more pronounced in the deeper area. Ecosystem-based approaches to fisheries management requires the development of multi-species modelling based on food web structure and species interactions. Our results emphasize the importance of modelling the two species and size classes separately, as they indicate clear trophic segregation
\end{abstract}

Keywords : Lophius, gut content, stable isotopes, trophic niche, trophic segregation, top predator 
The Ecosystem Approach to Fisheries Management is now recognized as a necessity, and numerous modelling studies are being conducted to support its implementation (Coll et al., 2015; Gascuel et al., 2011; Ramirez-Monsalve et al., 2016). The reliability of such models to provide diagnostics and scenarios depends on the availability and quality of the biological data on which they are based, especially those that describe biological interactions between species, including competition for food (Tremblay-Boyer et al., 2011). Feeding ecology is therefore a key component for understanding the position of marine organisms in the food chain and their relative roles in the ecosystem. Among the modelled species, it is essential to study predator's species as they exert important top-down control on the food web.

Anglerfish are known to be one of the top demersal predators in European waters. However, despite their high economic value, little is known about their biology and ecology (Farina et al., 2008; Landa et al., 2001). In the Celtic Sea, two species co-exist. Both have a wide mouth and use a modified first dorsal ray as a lure to ambush their prey. They are considered opportunistic predators, with whitefish, Crustacea and Cephalopoda identified as their main prey (Farina et al., 2008). Studies on the feeding ecology of anglerfish have been conducted in the Shetland Islands (Laurenson and Priede, 2005) and North Irish Sea (Crozier, 1989) for L. piscatorius and in the Cantabrian Sea (Preciado et al., 2006) and the Mediterranean Sea (Lopez et al., 2016; Negzaoui-Garali et al., 2008; Stagioni et al., 2013) for L. budegassa. However, to our knowledge no study investigated their feeding ecology in the Celtic sea.

The aim of this study was to investigate anglerfish feeding ecology in the Celtic sea using two complementary analyses. Gut content analysis was used to provide a snapshot of the composition of prey recently ingested by the two species. Stable isotope analysis of carbon and nitrogen was performed to reflect the composition of prey assimilated over longer time periods (Vander Zanden et al., 2015). 
Fish were sampled during the EVHOE survey (part of the International Bottom Trawl Survey performed in November) using a GOV (Grande Ouverture Verticale) demersal trawl with a cod-end of 20-mm stretched mesh, towed for $30 \mathrm{~min}$ at a speed of approximately 3.5 knots by R/V "Thalassa" during day time. To account for potential ontogenetic diet shifts, size classes were determined according to the main modes observed in the size-distribution of each species, obtained in the same season during previous EVHOE campaigns (size split at $20 \mathrm{~cm}$ for L. budegassa and $25 \mathrm{~cm}$ for L. piscatorius). This is of the same order of magnitude than other size split reported in the literature (Laurenson and Priede, 2005; Lopez et al., 2016). To account for potential spatial variations of anglerfish prey, sampling was also performed in two contrasting areas: one shallow area between 30 and $120 \mathrm{~m}$ depth (hereafter referred to as area A) and a deeper one ranging from 121 to $259 \mathrm{~m}$ depth (hereafter referred to as area B), Figure 1. Numbers of studied individuals per species, size class and area are given in Table 1.

Only individuals that had at least one prey item in their gut contents were considered for the analyses. Prey were identified to the lowest taxonomic level possible and grouped to highlight the main contributors to predator diet (e.g., Crustacea, Cephalopoda, other invertebrates). As anglerfish are known to be piscivorous, fish prey were grouped in a more detailed manner than other prey (e.g., by order such as Gadiformes, by family such as Gobiidae, or by species such as Trachurus trachurus). Several metrics were calculated to characterize feeding strategies and to compare the diet between different groups of individuals: the relative abundance and occurrence of prey, the Shannon index (Shannon, 1949) and the Schoener overlap index (Schoener, 1970).

On a subset of individuals (Table 1), a sample of white dorsal muscle was dissected for determination of $\delta^{15} \mathrm{~N} \delta^{13} \mathrm{C}$ isotopic ratio. Trophic level (TL) of anglerfish were calculated following the Post equation (Post, 2002), with a trophic enrichment factor of 3.4\%o (Minagawa and Wada, 1984) and Pectinid bivalves collected as primary consumers in the two areas as trophic baseline ( $\mathrm{TL}=2.5$; Jennings and Warr, 2003). Effects of anglerfish groups (species/length class) and area were investigated through 
two-way analysis of variance (ANOVA) on TL values after having checked their normal distribution by the mean of the Jarke-Bera test (1987). The ANOVA was followed by Tukey multiple-comparison tests. Isotopic niches were considered using Standard Ellipse Area (SEAc, (Jackson et al., 2011)) for the two species, size classes and areas. All the statistical analyses were performed using R 3.1.3 software (R Development Core Team, 2015).

Mean prey numbers per fish (Table 1) ranged between 1.1 and 2.5, with a maximum for large L. piscatorius in area B. Thirty-four taxa compose the diet of L. piscatorius and 32 that of L. budegassa. L. piscatorius had mainly fish prey (maximum: 100\%, Table S1), as did L. budegassa (maximum: 84\%), except for small individuals in area A, where Crustacean occurrence was the highest (62.5\%). Figure 2 shows that for both areas, demersal and pelagic fishes such as Gadiformes, Trachurus trachurus and Scomber scombrus accounted for more than $60 \%$ of the diet of large L. piscatorius. Crustacean taxa were less observed than fish in the gut contents of the two species, and were totally absent from large L. piscatorius in area B. Cephalopod and other macro-invertebrates (Scaphopods, Gastropods, Bivalves, Polychaetes and Ophiurids) prey were less frequent (from 0 to 33\%, Table S1). Diet composition of large L. piscatorius was quite similar between areas (Table S2 and Figure 2). For the small size class, the relative proportions of fish and invertebrates also remained consistent between the two areas, but fish species composition varied with an increase of Gobiidae and a lower proportion of Gadiformes in area B compared to area A. In contrast, L. budegassa had a more balanced diet than L. piscatorius, with 25 to $50 \%$ of benthic prey: Crustaceans (mainly shrimps and squat lobsters), flatfish and Gobiidae, depending on the area. Our results support the common finding that Lophius species are opportunistic predators that capture a wide range of prey types, since more than 50 taxa were identified in the gut contents. Fish were the primary food consumed by all size classes except for small L. budegassa in area A, for which $50 \%$ of the diet was composed of invertebrates. It is well known that anglerfish are sit-and-wait predators that preferentially feed on prey types that react to their lure, such as fish that themselves prey on mobile organisms and could confuse the lure 
with their own prey (Gordoa and Macpherson, 1990). The most common fish prey type observed was Gadiformes for large individuals of both species and Gobiidae for small individuals. This is consistent with previous studies performed in European waters (Azevedo, 1996). Though Lophius is a benthic species, pelagic fish (e.g. Trachurus trachurus and Scomber scombrus) have been identified in the diet of large individuals, as in other areas (Negzaoui-Garali et al., 2008). One must assume that these pelagic fishes approach the bottom sufficiently for the anglerfish to catch them.

ANOVA analysis showed significant differences between anglerfish groups $(\mathrm{p}<0.0001)$ and areas $(\mathrm{p}<0.0001)$. In each area the estimated TL (Figure 3) of small L. piscatorius was significantly lower than that of larger ones (mean of 3.3 and 4.1 for small and large, respectively, Tukey p-value $<0.0001$ for areas A and area B). For L. budegassa, the slight TL increase (from 3.8 to 4 between small and large fish) was not significant (Tukey p-value $=0.999$ and 0.963 for areas A and B, respectively). The TL obtained in this study are slightly lower than the value of other areas (Badalamenti et al., 2002). For both species, it is noteworthy that TLs in area B were significantly higher than in area A (Tukey pvalue between areas $>0.0001)$. In shallow water $(30-120 \mathrm{~m})$, the trophic level of L. piscatorius was around 3.31 (no difference between size classes) while in the deepest area ( $>120 \mathrm{~m}$ ) it was significantly higher for small (3.56) and large fish (4.49), nearing the 4.7 estimated in the North Sea for a 25.5-75.2 mm size range (Jennings et al., 2002). This suggests that prey are of lower trophic level in shallow water than in deeper water, especially for smaller fish.

Examination of Shoener's index (Table 2) suggests relatively weak diet overlaps between species and size classes in both areas. Overlaps were higher between the same size classes of the two species than between different size classes of the same species. The highest overlaps concerned large (0.49), and small fish (0.62) in area A and area B respectively. The isotopic niche was considered through SEAc estimates (Figure 4). For the same fish and length class, the SEAc were lower in area A than in area B

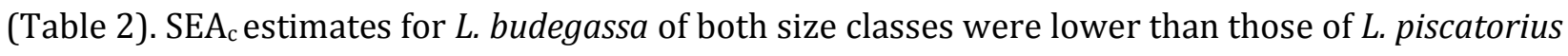
in the two areas. For this fish, no niche overlap (Table 2) was observed between the two size classes 
in area $\mathrm{A}$ and the niche overlap was quite small $\left(0.03 \% 0^{2}\right)$ in area B. Niche overlap between small and large L. budegassa was also weak in area A $\left(0.04 \% 0^{2}\right)$ and absent in area B. Maximum niche overlaps were observed in area A between large anglerfish of the two species $\left(0.07 \% 0^{2}\right)$, and in area B, between small ones on the one hand $\left(0.21 \%^{2}\right)$ and between large L. budegassa and small L. piscatorius on the other hand $\left(0.18 \% 0^{2}\right)$.

To summarize, trophic niche breadth was investigated through prey diversity and isotopic niche. Even if no clear pattern in term of number of prey could be detected between size classes, wider SEAc for smaller fish support a more diversified diet for small individuals. Prey diversity did not show any link to the area, while SEAc were systematically smaller in shallower waters, for each species and size class. Finally, the diet of L. budegassa was less diversified than that of L. piscatorius. The same pattern was observed for the isotopic niche with SEAc smaller for L. budegassa compared to L. piscatorius.

Ecosystem-based approaches to fisheries management requires the development of multi-species modelling based on food web structure and species interactions to investigate ecosystems functioning and responses to human disturbances. This type of data-oriented study is essential to inform and calibrate such trophic models. Considering the weak diet and SEA overlaps measured, we can conclude there is trophic segregation, limiting competition for food between the two species, especially in the shallow area. Our results suggest to model species and size classes separately to account for differences in feeding habits. We also highlighted that trophic preferences may vary between areas supporting the development of spatialized trophic models. Finally, our results suggest that the two species should be assess and manage separately instead of the currently in place common TAC (Total Allowable Catches).

Acknowledgements 
This work was part of the EATME project supported by France Filière Pêche and Région Bretagne.

The authors thank Guillaume Allanic and Margaux Denamiel for their help onboard the R/V Thalassa and in the laboratory.

\section{References}

Azevedo, M., 1996. Studying the feeding habits of anglerfish (Lophius spp) in Portuguese waters: a qualitative approach. ICES CM p. 199.

Badalamenti, F., D'Anna, G., Pinnegar, J.K., Polunin, N.V.C., 2002. Size-related trophodynamic changes in three target fish species recovering from intensive trawling. Marine Biology 141, 561-570.

Coll, M., Akoglu, E., Arreguin-Sanchez, F., Fulton, E.A., Gascuel, D., Heymans, J.J., Libralato, S., Mackinson, S., Palomera, I., Piroddi, C., Shannon, L.J., Steenbeek, J., Villasante, S., Christensen, V., 2015. Modelling dynamic ecosystems: venturing beyond boundaries with the Ecopath approach. Reviews in Fish Biology and Fisheries 25, 413-424.

Crozier, W.W., 1989. Age and growth of the anglerfish, Lophius piscatorius, in the north Irish sea. Fisheries Research 7, 267-278.

Farina, A.C., Azevedo, M., Landa, J., Duarte, R., Sampedro, P., Costas, G., Torres, M.A., Canas, L., 2008. Lophius in the world: a synthesis on the common features and life strategies. Ices Journal of Marine Science 65, 1272-1280. Gascuel, D., Guenette, S., Pauly, D., 2011. The trophic-level-based ecosystem modelling approach: theoretical overview and practical uses. Ices Journal of Marine Science 68, 1403-1416.

Gordoa, A., Macpherson, E., 1990. Food selection by sit and wait predator, the monkfish, Lophius Upsicephalus, off Namibia (south west africa) Environmental Biology of Fishes 27, 71-76.

Jackson, A.L., Inger, R., Parnell, A.C., Bearhop, S., 2011. Comparing isotopic niche widths among and within communities: SIBER - Stable Isotope Bayesian Ellipses in R. Journal of Animal Ecology 80, 595-602.

Jennings, S., Greenstreet, S.P.R., Hill, L., Piet, G.J., Pinnegar, J.K., Warr, K.J., 2002. Long-term trends in the trophic structure of the North Sea fish community: evidence from stable-isotope analysis, size-spectra and community metrics. Marine Biology 141, 1085-1097.

Landa, J., Pereda, P., Duarte, R., Azevedo, M., 2001. Growth of anglerfish (Lophius piscatorius and L-budegassa) in Atlantic Iberian waters. Fisheries Research 51, 363-376.

Laurenson, C.H., Priede, I.G., 2005. The diet and trophic ecology of anglerfish Lophius piscatorius at the Shetland Islands, UK. Journal of the Marine Biological Association of the United Kingdom 85, 419-424.

Lopez, N., Navarro, J., Barria, C., Albo-Puigserver, M., Coll, M., Palomera, I., 2016. Feeding ecology of two demersal opportunistic predators coexisting in the northwestern Mediterranean Sea. Estuarine Coastal and Shelf Science $175,15-23$.

Minagawa, M., Wada, E., 1984. Stepwise enrichment of 15N along food chains: Further evidence and the relation between $\delta 15 \mathrm{~N}$ and animal age. Geochimica et Cosmochimica Acta 48, 1135- 1140.

Negzaoui-Garali, N., Ben Salem, M., Capape, C., 2008. Feeding habits of the black anglerfish, Lophius budegassa (Osteichthyes : Lophiidae), off the Tunisian coast (central Mediterranean). Cahiers De Biologie Marine 49, 113122.

Post, D.M., 2002. Using stable isotopes to estimate trophic position: Models, methods, and assumptions. Ecology 83, 703-718.

Preciado, I., Velasco, F., Olaso, I., Landa, J., 2006. Feeding ecology of black anglerfish Lophius budegassa: seasonal, bathymetric and ontogenetic shifts. Journal of the Marine Biological Association of the United Kingdom 86, 877-884.

Ramirez-Monsalve, P., Raakjaer, J., Nielsen, K.N., Santiago, J.L., Ballesteros, M., Laksa, U., Degnbol, P., 2016. Ecosystem Approach to Fisheries Management (EAFM) in the EU - Current science-policy-society interfaces and emerging requirements. Marine Policy 66, 83-92.

Schoener, T.W., 1970. Non-synchronous spatial overlap of lizards in patchy habitats. Ecology 51, 408-418. Shannon, C.a.W., W, 1949. The mathematical theory of communication. University of Illinois Press, Urbana. Stagioni, M., Montanini, S., Vallisneri, M., 2013. Feeding habits of anglerfish, Lophius budegassa (Spinola, 1807) in the Adriatic Sea, north-eastern Mediterranean. Journal of Applied Ichthyology 29, 374-380. 
Tremblay-Boyer, L., Gascuel, D., Watson, R., Christensen, V., Pauly, D., 2011. Modelling the effects of fishing on the biomass of the world's oceans from 1950 to 2006. Marine Ecology Progress Series 442,169-U188.

Vander Zanden, M.J., Clayton, M.K., Moody, E.K., Solomon, C.T., Weidel, B.C., 2015. Stable Isotope Turnover and Half-Life in Animal Tissues: A Literature Synthesis. Plos One 10.

Tables and figures:

Table 1. Number of samples per species, size class and area for gut content and stable isotope analysis, with mean prey number per fish gut and total number of taxa.

Table 2. Shoener's and SEAc overlap index between species and size classes for the two areas studied.

Figure 1. Maps of sampled stations and area split. Triangles represent stations in area A and circles represent stations in area $B$.

Figure 2: Histogram of relative abundance of prey categories in the gut content of each species, size class and area combination.

Figure 3. Trophic level calculated for species, size classes and areas. LB indicates L. budegassa and LP indicates L. piscatorius. 1 refers to the small size class and 2 to the larger one. Grey boxplots represent area $\mathrm{A}$ and black boxplots area $\mathrm{B}$.

Figure 4. Projection of $S E A_{C}$ in the $\delta^{13} \mathrm{C} / \mathrm{TL}$ plane for the two species, size classes and areas. LB refers to L. budegassa and LP refers to L. piscatorius; 1 refers to small size class and 2 to the larger size class. 


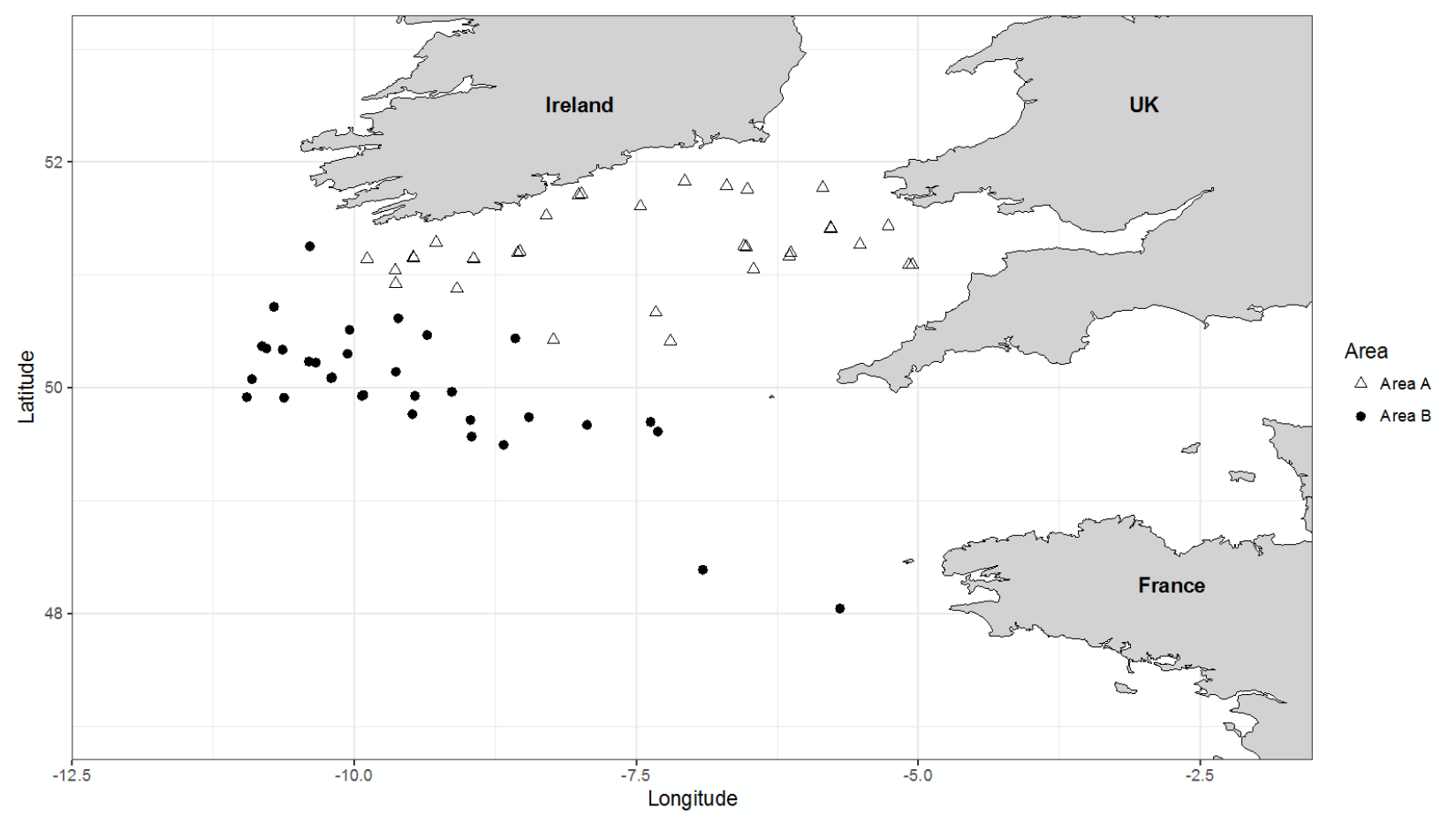

Figure 1 


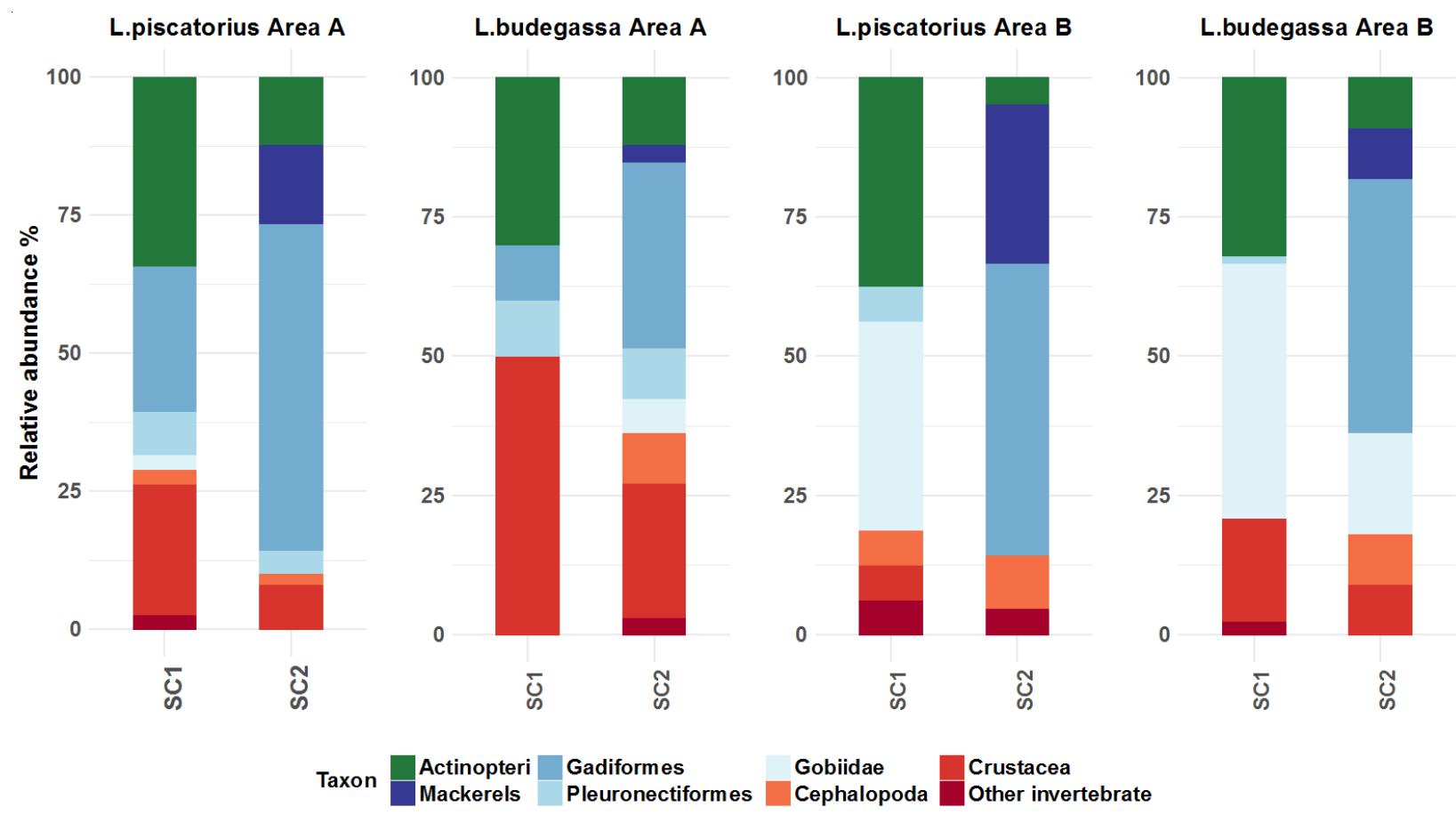

Figure 2 


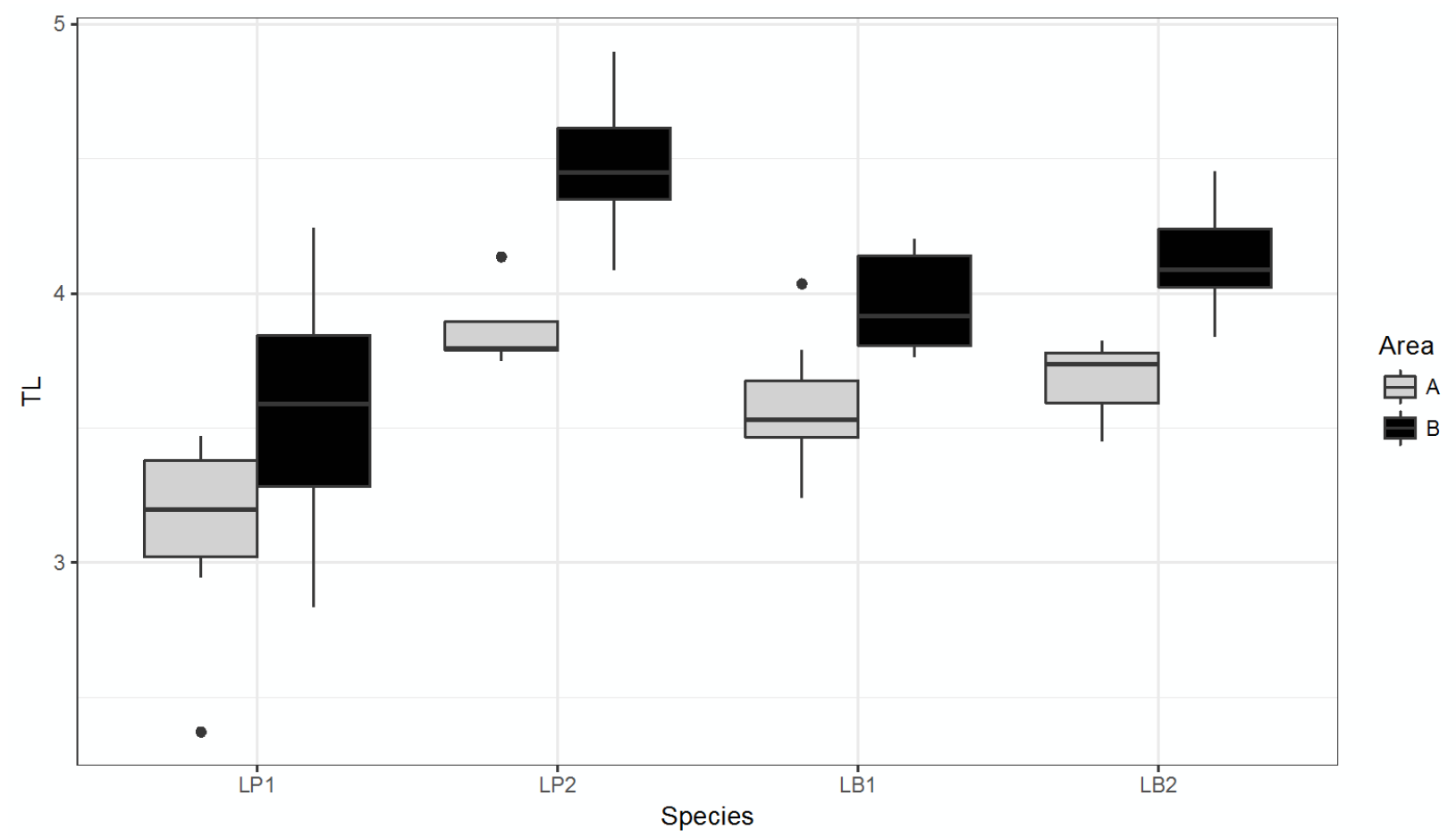

Figure 3 

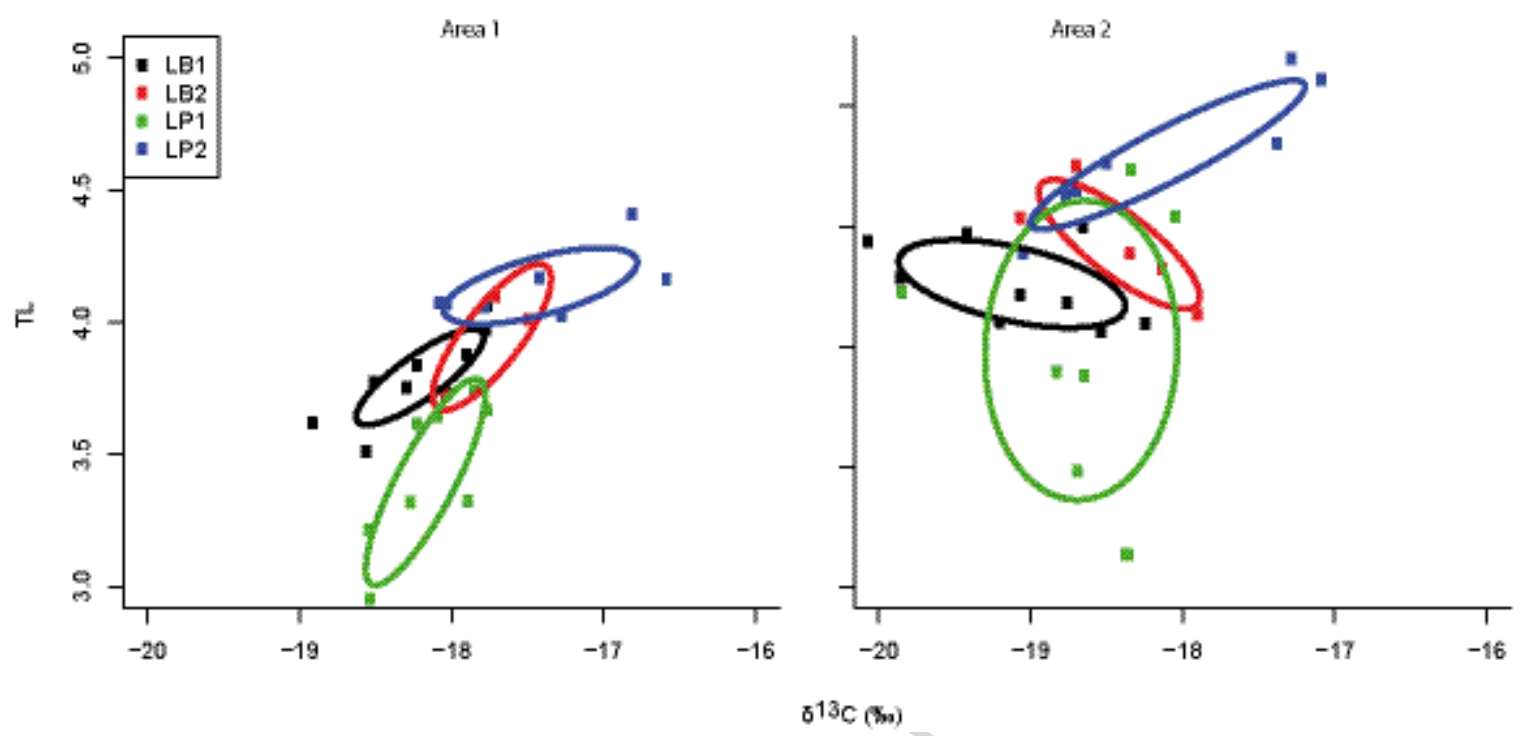

Figure 4 
Table 1

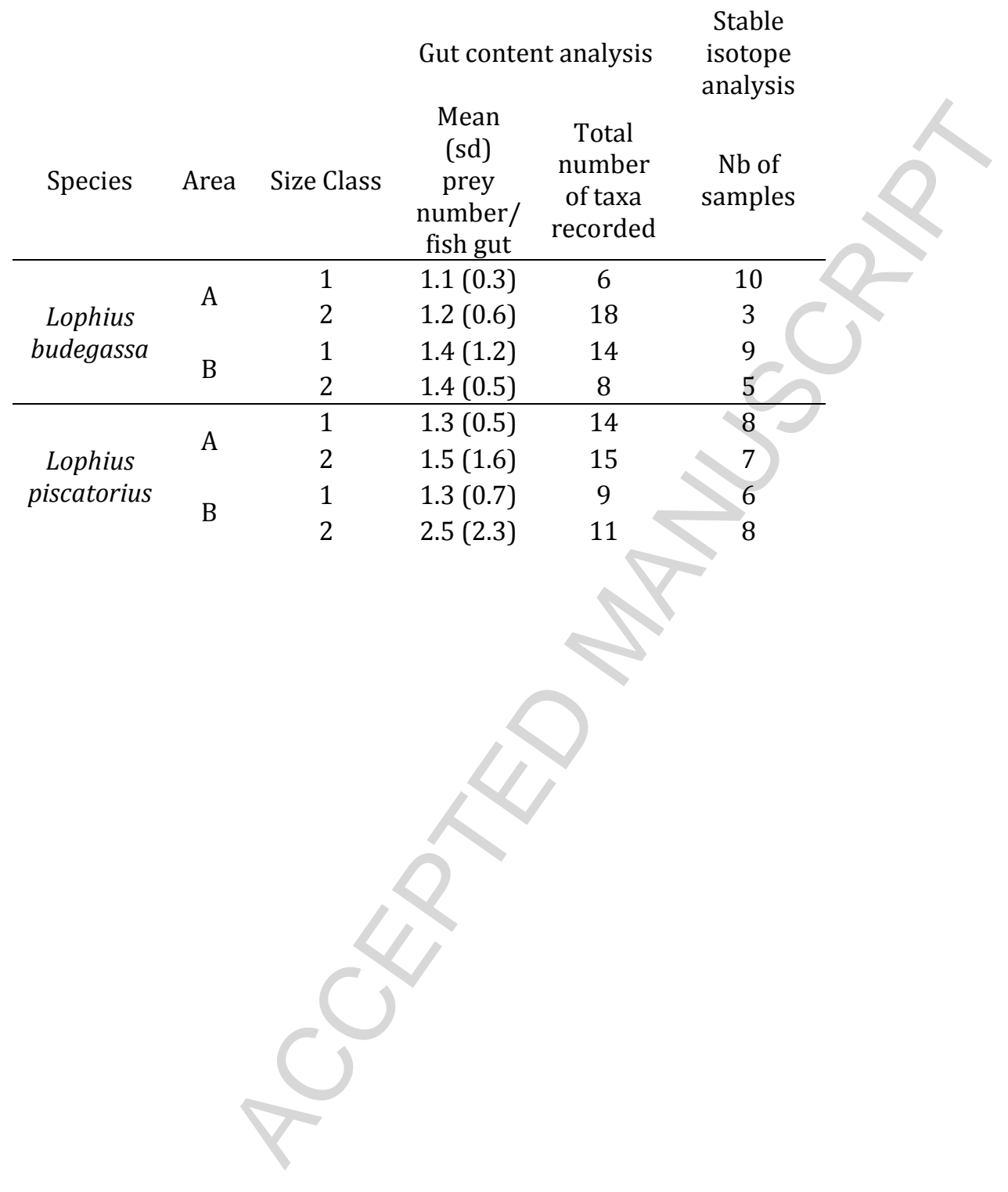


Table 2

Shoener's overlap index

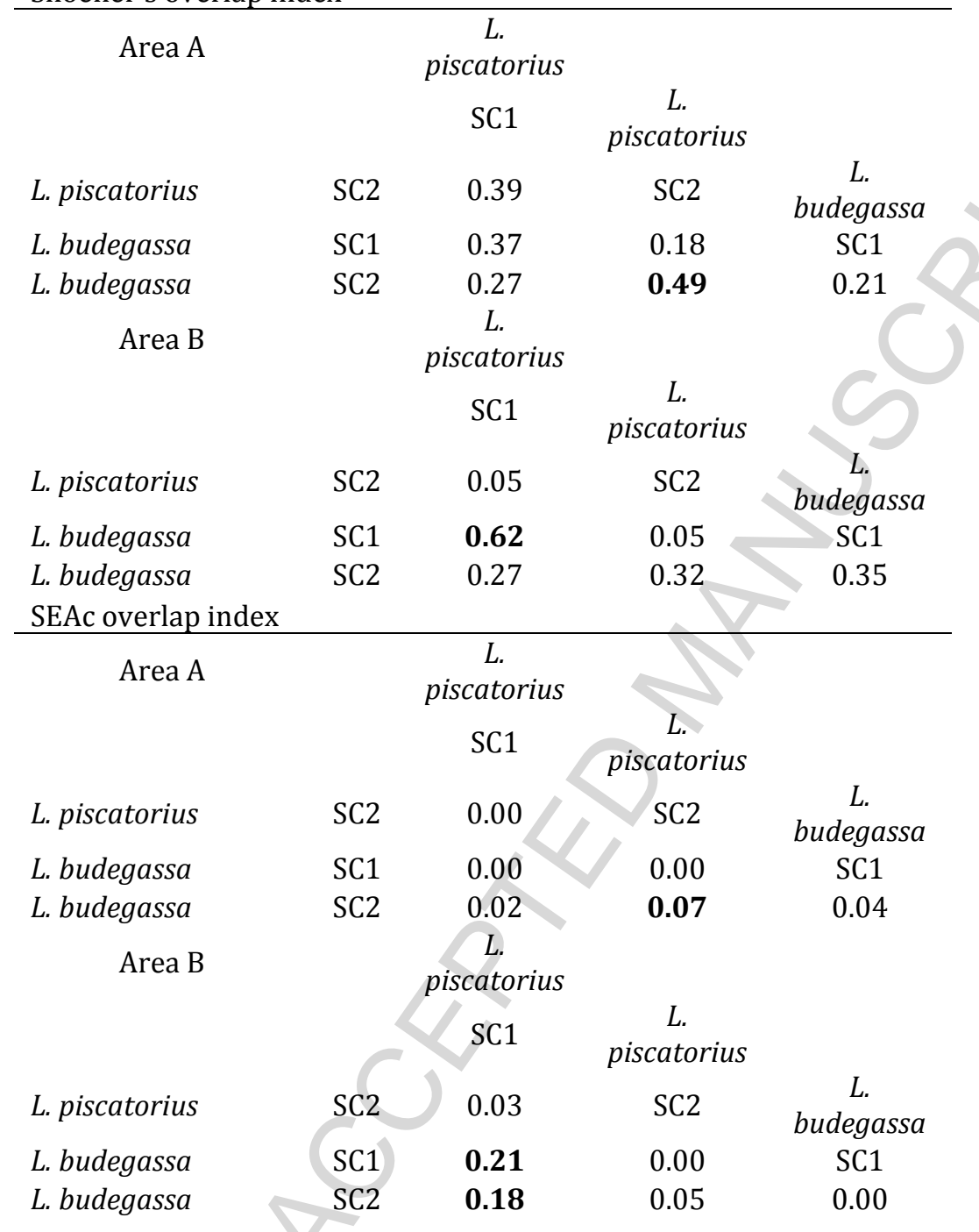

